\title{
Simultaneous detection and ribotyping of Clostridioides difficile, and toxin gene detection directly on fecal samples
}

\author{
Tessel M. van Rossen ${ }^{*} \mathbb{D}$, Joffrey van Prehn², Alex Koek ${ }^{1}$, Marcel Jonges ${ }^{1}$, Robin van Houdt ${ }^{\text {, }}$ \\ Rosa van Mansfeld ${ }^{1}$, Ed J. Kuijper ${ }^{2}$, Christina M. J. E. Vandenbroucke-Grauls ${ }^{1}$ and Andries E. Budding ${ }^{3}$
}

\begin{abstract}
Background: Clostridioides difficile is the most common cause of nosocomial diarrhea. Ribotyping of cultured strains by a PCR-based test is used to study potential transmission between patients. We aimed to develop a rapid test that can be applied directly on fecal samples for simultaneous detection and ribotyping of $C$. difficile, as well as detection of toxin genes.
\end{abstract}

Methods: We developed a highly specific and sensitive primer set for simultaneous detection and ribotyping of $C$. difficile directly on total fecal DNA. Toxin genes were detected with primers adapted from Persson et al. (Clin Microbiol Infect 14(11):1057-1064). Our study set comprised 130 fecal samples: 65 samples with positive qPCR for C. difficile toxin A/B genes and 65 C. difficile qPCR negative samples. PCR products were analyzed by capillary gel electrophoresis.

Results: Ribosomal DNA fragment peak profiles and toxin genes were detected in all 65 C. difficile positive fecal samples and in none of the 65 C. difficile negative samples. The 65 samples were assigned to 27 ribotypes by the Dutch reference laboratory. Our peak profiles corresponded to these ribotypes, except for two samples. During a C. difficile outbreak, patients were correctly allocated to the outbreak-cluster based on the results of direct fecal ribotyping, before $C$. difficile isolates were cultured and conventionally typed.

Conclusion: C. difficile ribotyping directly on fecal DNA is feasible, with sensitivity and specificity comparable to that of diagnostic toxin gene GPCR and with ribotype assignment similar to that obtained by conventional typing on DNA from cultured isolates. This supports simultaneous diagnosis and typing to recognize an outbreak.

Keywords: Clostridioides difficile, PCR ribotyping, Toxin genes, Infection control, Hospital epidemiology

\section{Background}

Clostridioides difficile is an anaerobic, spore-forming bacterium and the most common cause of hospitalassociated diarrhea. In severe cases, $C$. difficile infection (CDI) can lead to pseudomembranous colitis, toxic megacolon and bowel perforation. The attributable mortality

\footnotetext{
*Correspondence: t.vanrossen@amsterdamumc.nl

${ }^{1}$ Department of Medical Microbiology and Infection Control, Amsterdam Infection and Immunity Institute, Amsterdam UMC, Vrije Universiteit Amsterdam, PK 2X132, De Boelelaan 1117, Amsterdam, The Netherlands Full list of author information is available at the end of the article
}

of $C$. difficile infection in an endemic setting is approximately $5 \%[1,2]$. Hospital outbreaks of $C$. difficile occur often, presumably due to the large numbers of bacterial spores that can be excreted by symptomatic patients. Outbreaks threaten patient safety, and pose a substantial financial burden to healthcare. Incremental costs per CDI are estimated to be approximately $€ 5000$ (\$5700), but in outbreak-settings these can increase to $€ 7000$ $16,000(\$ 7.900-18.100)$ per patient $[3,4]$.

To detect $C$. difficile transmission between patients, bacterial strains need to be characterized beyond the species level. Furthermore, early recognition of original author(s) and the source, provide a link to the Creative Commons licence, and indicate if changes were made. The images or other third party material in this article are included in the article's Creative Commons licence, unless indicated otherwise in a credit line to the material. If material is not included in the article's Creative Commons licence and your intended use is not permitted by statutory regulation or exceeds the permitted use, you will need to obtain permission directly from the copyright holder. To view a copy of this licence, visit http://creativecommons.org/licenses/by/4.0/. The Creative Commons Public Domain Dedication waiver (http://creativeco mmons.org/publicdomain/zero/1.0/) applies to the data made available in this article, unless otherwise stated in a credit line to the data. 
hypervirulent strains is important for prompting institution of strict infection control measures, since these strains are associated with higher mortality and transmission rates [5-7]. A commonly used typing technique for $C$. difficile, which is recommended for surveillance purposes, is PCR ribotyping [8]. This method is based on strain-specific differences in number and length of the ribosomal 16-23S interspace regions (IS-regions). A drawback of the currently used PCR ribotyping methods is that they can only be performed on cultured C. difficile isolates [9-14]. This delays the time to results and eventual implementation of infection control measures. Therefore, Janezic et al. designed new primers and tested these directly on total fecal DNA; they obtained a specificity of $100 \%$ and a sensitivity of $84.8 \%$ [15].

Our objective was to develop ribotyping primers which could also be applied directly on fecal DNA but with higher sensitivity, while retaining specificity. Ideally, direct ribotyping on feces should be as sensitive as $C$. difficile quantitative PCR (qPCR), as this would make it possible to use it as first-line diagnostic assay. We assessed this new method during a suspected outbreak of $C$. difficile in our hospital. Thereafter, we validated our primers and our optimized protocol in a larger sample set of $C$. difficile-positive and -negative stools to assess sensitivity, specificity, and typing performance.

\section{Methods}

\section{Primers}

Primers were designed with AliView (Uppsala University, Uppsala, Sweden) based on alignment of 20 downloaded C. difficile sequences from the Silva database (Max Planck Institute for Marine Microbiology and Jacobs University, Bremen, Germany) [16]. Specificity was assessed by comparison to $C$. difficile closest phylogenetic relatives, $C$. sordellii and C. bifermentans. Primers were targeted to the 16S-23S ribosomal DNA interspace regions (IS-regions). Since we aimed to perform ribotyping directly in fecal samples comprising high loads of nonC. difficile bacteria, we attempted to improve specificity for $C$. difficile by shifting the primers from the more conserved $16 \mathrm{~S}$ region towards the IS-region. We observed that different primers were needed for amplification of short ( $<400$ nucleotides) and long ( $>400$ nucleotides) IS-fragments. This resulted in the four primers shown in Additional file 1: Table 1. Using BLAST, we observed a $100 \% / 100 \%$ match with the 20 C. difficile sequences and no cross reactivity with C. sordellii and C. bifermentans, which are taxonomically closest to $C$. difficile. Forward ribotyping primers were FAM-labeled for analysis with ABI Prism 3500 GeneticAnalyzer (Applied Biosystems, Foster City, California, USA). For detection of toxin A $(t c d A)$, toxin $\mathrm{B}(t c d B)$, binary toxin $(c d t A, c d t B)$ genes, we used the primers designed by Persson et al. (Additional file 1: Table 1) [17]. Forward toxin gene primers were HEX-labeled.

\section{Fecal samples and $C$. difficile strains}

During the optimization phase of our direct ribotyping technique, a $C$. difficile outbreak was suspected in the Intensive Care Unit (ICU) of our institution. To assess the clinical applicability of our method, we applied this new technique directly to the fecal samples of eleven patients with positive $C$. difficile tests. Thereafter, we validated our method in a larger study set of 130 fecal samples: in addition to the eleven samples from the outbreak, we randomly selected 54 fecal samples with positive qPCR for $C$. difficile toxin A and/or B genes (the standard diagnostic test for $C$. difficile detection in our laboratory) and $65 C$. difficile qPCR negative samples, derived from the diagnostic laboratory. For control, $C$. difficile strains were cultured from all 65 fecal samples with positive qPCR for $C$. difficile toxin A and/or B genes. Culture was performed anaerobically on selective $C$. difficile agar plates (bioMérieux, Marcy l'Etoile, France) according to standard protocol of our diagnostic microbiological laboratory. All 65 C. difficile strains were also sent to the Dutch National Reference Laboratory at Leiden University Medical Center (LUMC) for conventional ribotyping using a standardized protocol [18]. These ribotypes served as reference. As control samples we randomly selected 65 fecal samples with negative qPCR's for $C$. difficile from the routine diagnostic microbiology laboratory. Of these C. difficile negative samples, three were positive in PCR for Salmonella spp., six for Campylobacter spp., one for Shigella spp., one for both Campylobacter spp. and Shigella spp., one for parechovirus, one for norovirus and one for enterovirus. To assess potential cross-reactivity in vitro, we also performed direct ribotyping on $C$. difficile's closest taxonomically relatives, $C$. sordellii and $C$. bifermentans. These isolates were derived from the diagnostic laboratory and identified with the MALDI-TOF MS (Matrix-Assisted Laser Desorption-IonisationTime of Flight Mass Spectrometry, VITEK MS, BioMerieux). All fecal samples were obtained from hospitalized patients with diarrhea, admitted to Amsterdam UMC, location VUmc, between 2016 and 2018 (Additional file 1: Table 2).

\section{DNA isolation from fecal samples and C. difficile strains}

DNA isolation was performed according to standard protocol of our diagnostic microbiological laboratory. Within $36 \mathrm{~h}$ after arrival at the laboratory, fecal samples were stored at $-80{ }^{\circ} \mathrm{C}$. For this study, samples were thawed and a pea-sized amount of feces (100-400 mg) was collected with a swab. In case of liquid feces, swabs 
were immersed halfway into the liquid. Swabs were placed in Eppendorf tubes, vortexed and incubated in $1 \mathrm{ml}$ S.T.A.R. buffer (Roche, Basel, Switzerland) at $-80{ }^{\circ} \mathrm{C}$ for $1 \mathrm{~h}$ or overnight. Subsequently, tubes were heated at $100{ }^{\circ} \mathrm{C}$ for $10 \mathrm{~min}$. After centrifugation for $10 \mathrm{~s}$ at $4000 \mathrm{rpm}, 300 \mu \mathrm{l}$ of the supernatant fraction was suspended in $300 \mu \mathrm{l}$ lysis buffer for DNA isolation with MagNaPure96 (Roche, Basel, Switzerland). C. difficile strains were collected with a $1 \mu \mathrm{l}$ inoculation loop and stored in $200 \mu \mathrm{l} \mathrm{TE}$-lysis buffer (Tris-HCl, EDTA, pH 8.0, Promega V6231) at $-20{ }^{\circ} \mathrm{C}$. After thawing, suspensions were vortexed for $15 \mathrm{~s}$ and centrifuged for $3 \mathrm{~min}$ at 12,000 rpm. The supernatant was diluted 1:10 $(1 \mu \mathrm{l}$ supernatant and $9 \mu \mathrm{l}$ nuclease free water) and $15 \mu \mathrm{l}$ Mastermix was added for the PCR reaction.

\section{Amplification and analysis}

For both PCR reactions of direct ribotyping and toxin gene detection, extracted DNA of cultured strains was diluted 1:10; DNA of fecal samples was used undiluted. When inhibition of the PCR reaction was suspected (no peaks or primer-dimer signal detected), the reaction was repeated with total fecal DNA diluted 1:5 to identify a possible false negative result due to inhibition. PCR mixtures for ribotyping, with a final volume of $25 \mu \mathrm{l}$ consisted of $10 \mu \mathrm{l}$ DNA and $15 \mu \mathrm{l}$ of IS-pro mastermix (inBiome bv) with $0.13 \mu \mathrm{M}$ of each primer. PCR mixtures for toxin gene detection, with a final volume of $25 \mu \mathrm{l}$ consisted of $10 \mu \mathrm{l}$ DNA and $15 \mu \mathrm{l}$ IS-pro mastermix (inBiome bv) with $0.6 \mu \mathrm{M}$ of each $t c d A$-primer, $0.4 \mu \mathrm{M}$ $t c d B$-F primer, $0.2 \mu \mathrm{M}$ of each $t c d B-\mathrm{R}$ primer, 0.05 of each $c d t A-\mathrm{F}$ primer, $0.1 \mu \mathrm{M} c d t A$-R primer and $0.1 \mu \mathrm{M}$ of each $c d t B$-primer. PCR mixtures for ribotyping and toxin gene detection were placed in separate wells. Amplifications were carried out with GeneAmp PCR system 9700 (Applied Biosystems, Foster City, CA, USA). Cycling conditions for both ribotyping and toxin gene detection PCRs were $95{ }^{\circ} \mathrm{C}$ for $10 \mathrm{~min}, 12$ cycles (with $0.7^{\circ} \mathrm{C}$ decrements at every cycle) of $94{ }^{\circ} \mathrm{C}$ for $30 \mathrm{~s}, 65^{\circ} \mathrm{C}$ for $30 \mathrm{~s}$ and $72{ }^{\circ} \mathrm{C}$ for $1 \mathrm{~min}$ and 23 cycles of $94{ }^{\circ} \mathrm{C}$ for $30 \mathrm{~s}, 56^{\circ} \mathrm{C}$ for $30 \mathrm{~s}$ and $72{ }^{\circ} \mathrm{C}$ for $1 \mathrm{~min}$, followed by extension at $72{ }^{\circ} \mathrm{C}$ for $11 \mathrm{~min}$. Afterwards PCR product was stored at $4{ }^{\circ} \mathrm{C}$. Within $12 \mathrm{~h}, 5 \mu \mathrm{l}$ PCR product and $20 \mu \mathrm{l}$ formamide with custom size marker (eMix, InBiome, Amsterdam, the Netherlands) was pipetted in a 96-wells plate, heated at $94{ }^{\circ} \mathrm{C}$ for $3 \mathrm{~min}$ and cooled down to $4{ }^{\circ} \mathrm{C}$. DNA fragment analysis was performed with ABI Prism 3500 GeneticAnalyzer (Applied Biosystems, Foster City, California, USA) in separate capillaries for direct ribotyping (FAM-labeled primers) and toxin gene detection (HEXlabeled primers). DNA fragment lengths including intensity were visualized and analyzed with TIBCO Spotfire (TIBCO Software Inc., Palo Alto, California, USA). To standardize the amount of bacterial DNA, we calculated relative intensity of each ribosomal DNA fragment peak by dividing the absolute intensity of each peak of a sample by the absolute intensity of the highest peak of that sample. Clustering of fecal samples based on ribotype DNA fragment peak profile similarity was performed by UPGMA (Unweighted Pair Group Method with Arithmetic Mean), with cosine correlation as distance measure and average value as ordering weight. Toxin gene-specific peaks were defined according to DNA fragment sizes described by Persson et al.: $t c d A$ ( $629 \mathrm{bp}), t c d B(410 \mathrm{bp})$, $c d t A$ (221 bp) and $c d t B(262 \mathrm{bp})$. Presence or absence of toxin gene peaks was scored binarily using an intensity cutoff of 3000 RFU.

\section{Results}

Application of direct ribotyping during an outbreak with $C$. difficile

During the optimization phase of our direct ribotyping technique, a $C$. difficile outbreak was suspected in the ICU. In our institution, the standard typing technique for C. difficile is Amplified Fragment Length Polymorphism (AFLP) on cultured strains. The suspected outbreak cluster involved six patients with the same $C$. difficile AFLPtype. During this outbreak, samples of five other patients became positive for $C$. difficile by qPCR or toxin enzyme immune assay (EIA). We performed direct ribotyping on total fecal DNA of all eleven patients. The six patients with the same $C$. difficile AFLP-type had identical ribotype peak profiles (Fig. 1). In the five other patients that became positive for $C$. difficile during the outbreak, direct ribotyping enabled us to allocate 1 of the 5 patients to the outbreak-cluster and 4/5 patients outside the outbreak-cluster (Fig. 1). Importantly, results of direct fecal ribotyping were obtained before strains were cultured and conventionally typed by AFLP.

\section{C. difficile PCR ribotyping and toxin gene detection}

After our first experience with direct ribotyping during the outbreak, we aimed to validate our technique with a larger sample set of 130 fecal samples (including the 11 samples collected during the outbreak). With the ribotype primers we amplified DNA of a total of 65 fecal samples that were previously proven to contain $C$. diffcile by qPCR for $C$. difficile toxin A and/or B genes (the standard diagnostic test for $C$. difficile detection in our laboratory). Mean $\mathrm{Cp}$ value (crossing point at which the amplification curve crosses the vertical threshold line; this is inversely associated with the $C$. difficile load) of C. difficile toxin gene qPCR was 33 (range 27-40 cycles, Additional file 1: Table 2). DNA fragment peak profiles were obtained from all 65 fecal samples (3 after 1:5 dilution because of inhibition) and from all 65 cultured 


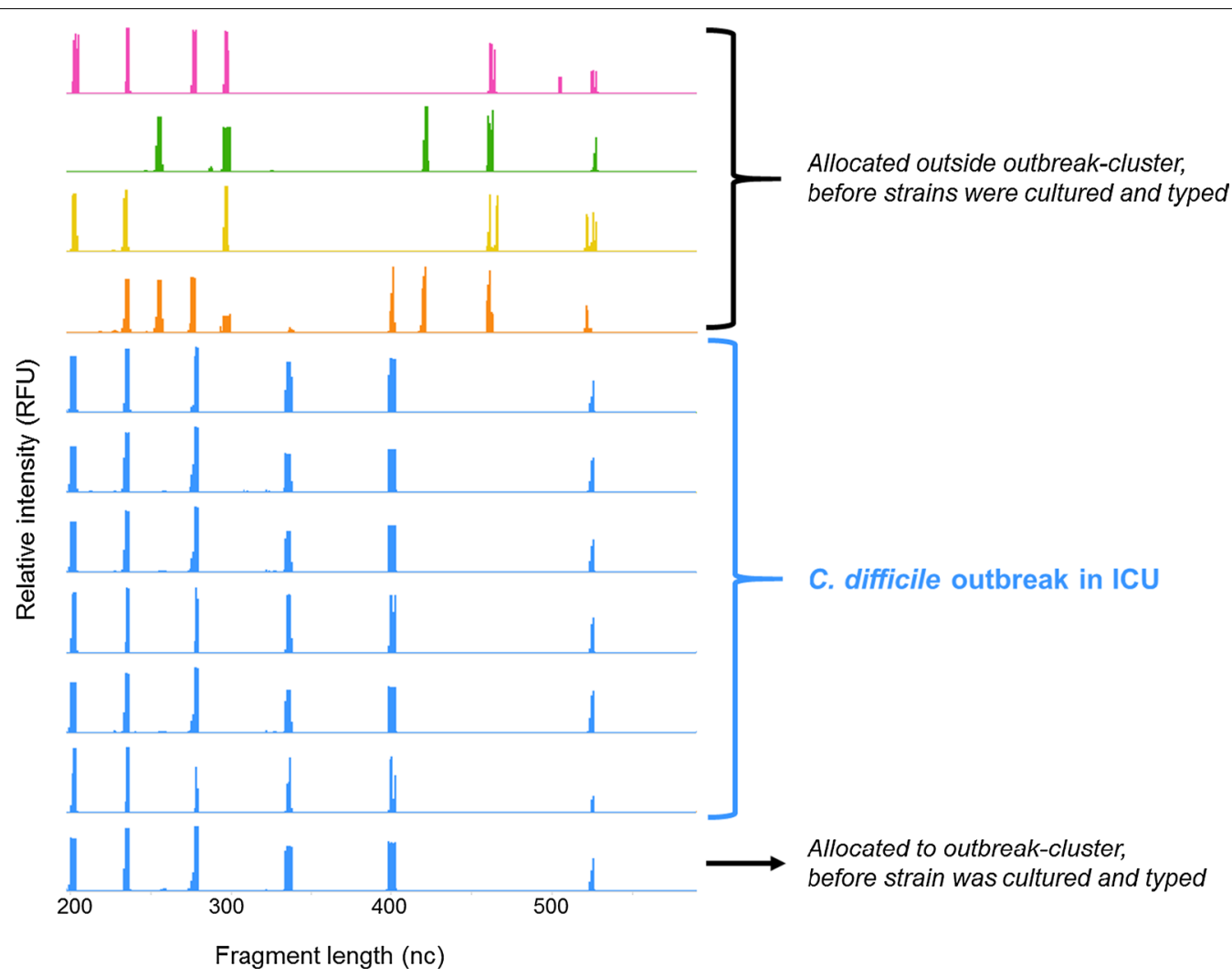

Fig. 1 Ribosomal DNA fragment profiles in fecal samples of eleven patients with positive C. difficile toxin A and/or B genes qPCR. Bacterial transmission was suspected in seven patients with identical peak profiles (blue). $\mathrm{nc}=$ nucleotides, RFU = relative fluorescence units

strains. Hence, the sensitivity of the new primers set for toxigenic C. difficile detection was $100 \%(\mathrm{n}=65,95 \%$ Confidence Interval (CI) 94.5-100\%).

We observed DNA fragment peaks ranging in size from approximately 200 to 590 nucleotides, consistent with published studies when corrected for differences in primer binding sites $[11,12,14,15]$. Also the number of DNA fragments was in agreement with previously described ribotype profiles, and varied between 5 and 10 $[11,12,14,15]$.

To examine the specificity of our primers for C. difficile detection, we applied the primers to total DNA obtained from $C$. bifermentans and $C$. sordellii strains and 65 fecal samples with negative qPCR for $C$. difficile toxin genes. Of these samples, fourteen were positive by diagnostic PCR's for other bacterial species and viruses that are well-known causes of diarrhea such as Campylobacter spp., Salmonella spp. and norovirus. No DNA fragment peak profiles were detected in these samples, indicating a diagnostic specificity of $100 \%(n=65,95 \%$ CI 94.5-100\%).

To assess reproducibility, DNA isolation and direct ribotyping was performed in duplicate on a subset of 40 fecal samples with a positive qPCR for $C$. difficile toxin
A and/or B genes. DNA fragment peak profiles were observed in 40/40 paired fecal samples. Profiles of 36/40 paired fecal samples were $100 \%$ identical (90\%). All discrepancies were found in larger DNA fragments $(>400)$ in low load samples $(C$. difficile toxin A and/or B genes qPCR Cp values 35-39).

To examine possible technical issues of ribotyping directly on feces-for example decreased intensity of DNA fragment peaks due to PCR inhibition or appearance of nonspecific peaks due to an excess of fecal DNAthe peak profile of each fecal sample was compared with that of its corresponding cultured strain, see Fig. 2 for example. Peak profiles of 61/65 paired fecal samples and strains were completely identical (94\%). In 3/65 samples we observed 1 peak difference. These samples had a low bacterial load in qPCR (Cp values 35-39); and it was one of the larger DNA fragment peaks ( $>400$ nucleotides) that was missing. In $1 / 65$ samples we observed that the three largest DNA fragments in the strain profile were missing in the profile of the fecal sample (Cp value 29).

For detection of toxin $\mathrm{A}(t c d A)$, toxin $\mathrm{B}(t c d B)$ and binary toxin $(c d t A, c d t B)$ genes directly on total fecal DNA we used primers designed by Persson et al. and added these in our study set (Fig. 3) [17]. All C. difficile 


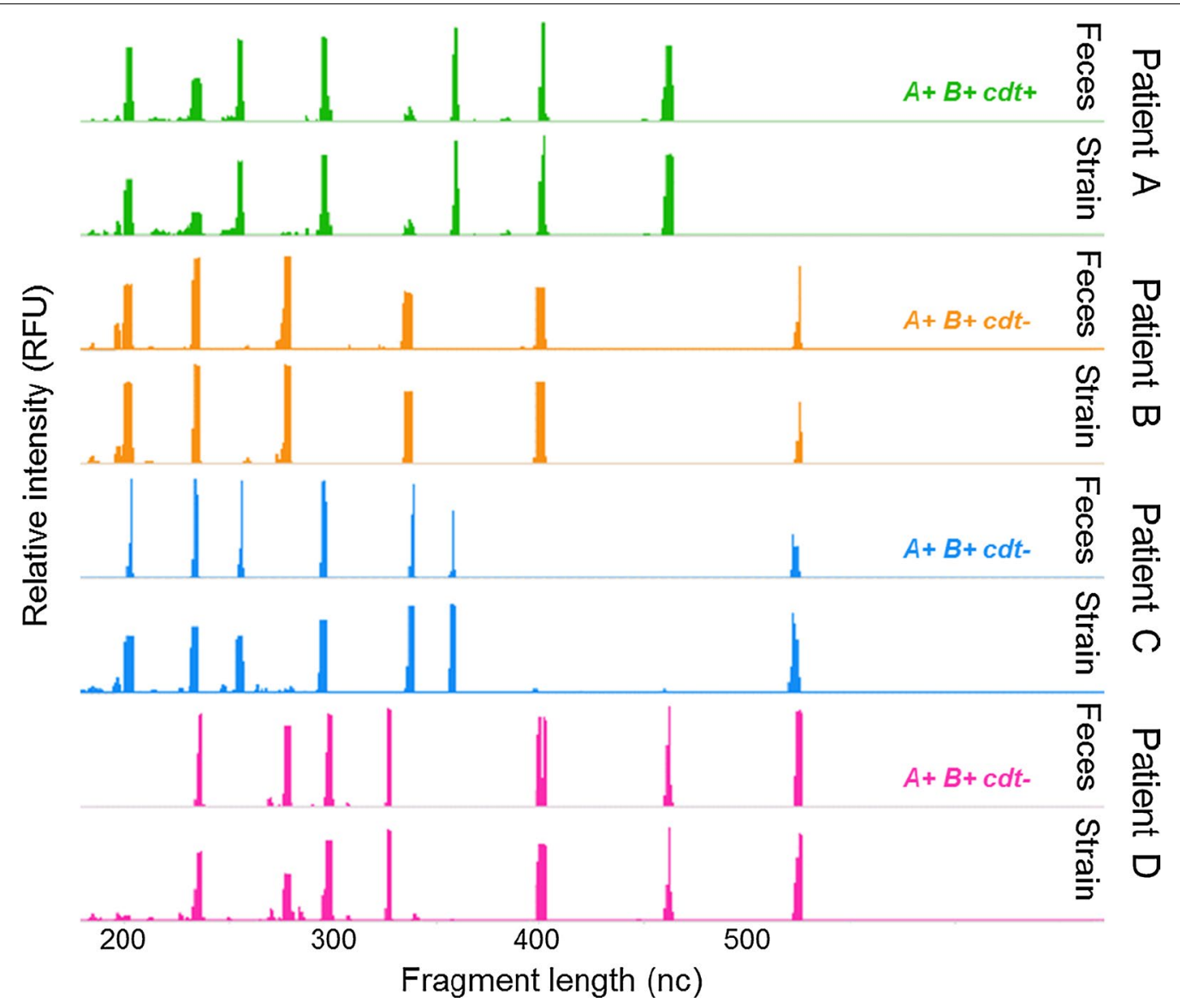

Fig. 2 Examples of DNA fragment peak profiles from four fecal samples and their corresponding cultured strains. $n c=$ nucleotides, RFU $=$ relative fluorescence units, $A=$ toxin $A$ gene, $B=$ toxin $B$ gene, $c d t=$ binary toxin genes.

positive fecal samples showed at least one toxin gene peak, whereas no peaks were observed in the C. difficile negative fecal samples. The presence of toxin genes specific for different ribotypes was consistent with literature [11, 19-21]. In one sample with RT190, toxin A, B and binary toxin $B$ genes were detected but not binary toxin A gene. This could be due to non-specificity of our assay; however, $C$. difficile strains with presence of binary toxin $\mathrm{B}$ but not binary toxin A gene have been described [22, 23]. Also, we detected both toxin A and $B$ gene peaks in RT017 samples, while this ribotype is known to produce only toxin B [24-26]. This was observed and clarified previously by Persson et al.: "The primers used to amplify toxin A gene are located upstream of the repetitive region in the $3^{\prime}$-end which, in some strains, contains various deletions that render the gene product non-detectable by EIA methods. Therefore, strains that are TcdA-negative due to 3 '-end deletions are still tcdA-positive according to the present multiplex PCR." [17].

\section{Reference ribotypes obtained by conventional ribotyping} of strains

Conventional ribotyping of all $65 \mathrm{C}$. difficile strains that were cultured from the 65 fecal samples was performed by the Dutch National Reference Laboratory. These ribotyping results served as reference. The Reference Laboratory could not determine the ribotype of $2 / 65$ strains due to unknown or absent band patterns. A 'probable ribotype' was determined in 5/65 strains since the band patterns of these strains were highly similar to patterns of reference strains except for a 1 or 2 bands difference. Overall, 63/65 strains of our study set were assigned to 27 different reference ribotypes.

\section{Clustering of fecal samples based on peak profile similarity} We assessed if direct ribotyping on fecal samples was feasible as first screening tool for detection of a clonally related $C$. difficile cluster by performing cluster analysis based on ribosomal DNA fragment profile similarity. A heat map and dendrogram were created based on peak 


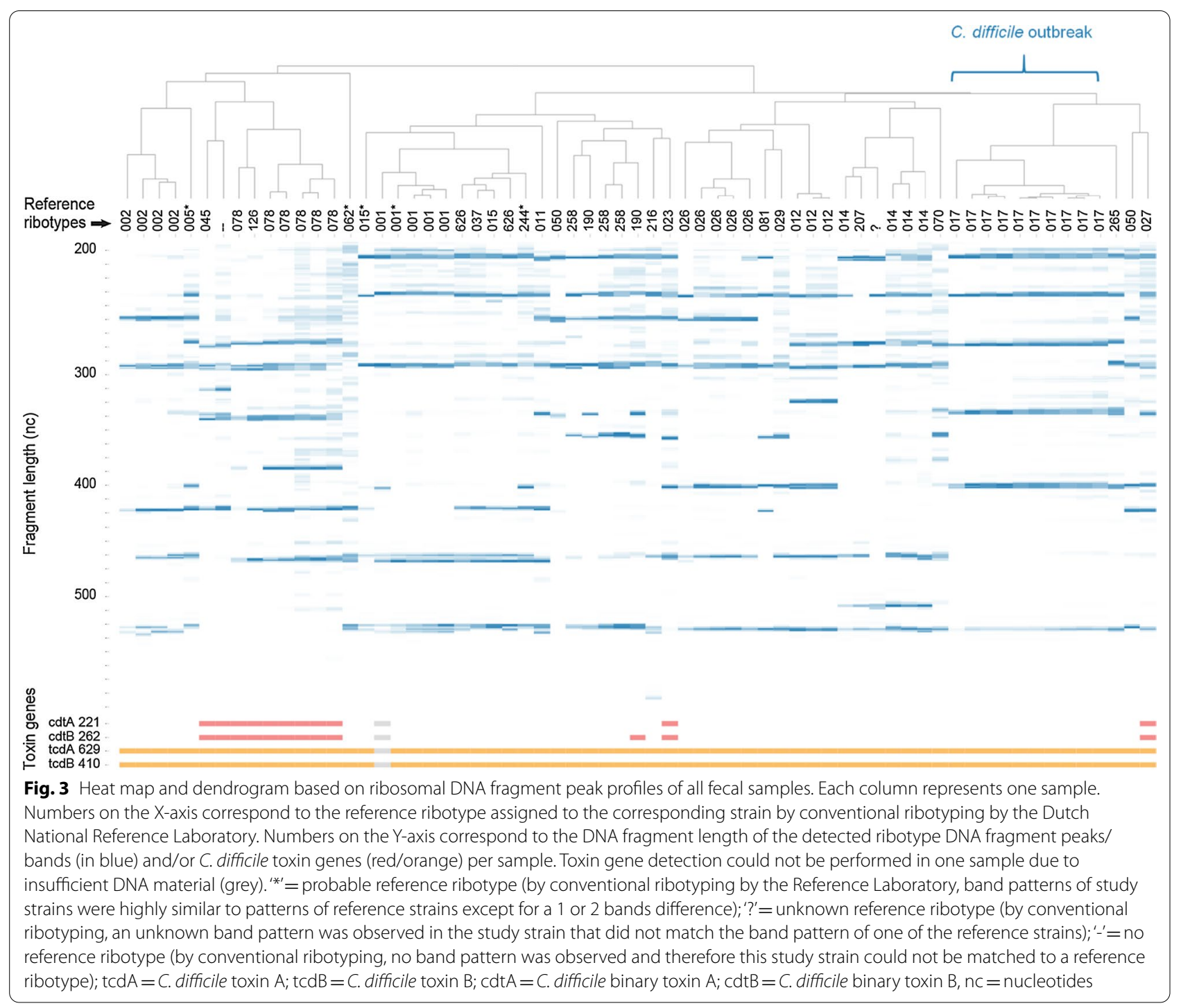

profiles of all 65 fecal samples with positive qPCR for $C$. difficile toxin A/B genes (Fig. 2). The resulting clusters consisted of fecal samples containing the same $C$. diffcile ribotypes as determined by the Reference Laboratory (for example, one cluster consisted of four fecal samples that all contained RT002), except for two samples: one with RT002 and one with RT050. The ribotyping patterns in both samples lacked the larger DNA fragment peaks when compared to profiles of samples with the same reference ribotype.

In conventional ribotyping, a pattern with a single band difference is usually considered as a different ribotype. Using this definition, we assessed the performance of direct ribotyping on feces for ribotype assignment by comparing peak profiles of samples with the same reference ribotype. We observed identical peak profiles in 43/48 (90\%) fecal samples containing identical ribotypes
(RT001: 4 out of 5 profiles were identical, RT002: $\mathrm{n}=3 / 4$, RT012: $\mathrm{n}=3 / 3$, RT014: $\mathrm{n}=4 / 4$, RT015: 2/2, RT017: $\mathrm{n}=10 / 10$, RT026: $\mathrm{n}=5 / 5$, RT050 $\mathrm{n}=0 / 2$, RT078: $\mathrm{n}=5 / 6$, RT190: $\mathrm{n}=2 / 2$, RT258: $\mathrm{n}=3 / 3$, RT626: $\mathrm{n}=2 / 2$ ).

\section{Discussion}

We developed a highly sensitive and specific set of PCR primers for $C$. difficile ribotyping that can be applied directly on fecal samples. Samples containing identical strains clustered together based on ribotype peak profile similarity. During an outbreak of C. difficile RT017 in our institution, patients were correctly allocated to- or outside the outbreak-cluster before $C$. difficile isolates were cultured and conventionally typed.

To the best of our knowledge, this is the third study on C. difficile ribotyping directly on fecal samples. Several 
multiplex PCRs for the detection of RT027/NAP1 strains do exist, but these are targeted at specific RT027 gene fragments and are not suitable for distinction between multiple ribotypes. Janezic et al. were the first to describe a method for direct $C$. difficile ribotyping on feces in 2011 using agarose gel electrophoresis [15]. They detected DNA fragments in 86 out of 99 C. difficile positive samples, resulting in a sensitivity for $C$. difficile detection of $86.9 \%$. Recently, another research group applied the primers of Bidet et al., which were originally developed for ribotyping on cultured strains, directly on fecal DNA $[12,27]$. However, one third of stool samples required broth enrichment for $24 \mathrm{~h}$ before ribosomal DNA fragments could be detected. Cp values of ribotyping and toxin B gene qPCRs were significantly lower in stools in which direct ribotyping was successful, compared to enriched stools. With our primers set, we detected DNA fragments in all $65 \mathrm{C}$. difficile positive samples, resulting in a sensitivity of $100 \%$ (95\% CI $94.5-100 \%)$ without the need of broth enrichment. The specificity of our PCR was $100 \%(n=65,95 \%$ CI $94.5-100 \%)$; this was the same specificity as obtained by Janezic et al. [15]. The specificity of the method of Lloyd et al. is unclear since they did not include C. difficile negative samples [27].

Previous studies showed that in $5-10 \%$ of patients with CDI, two or more $C$. difficile strains can be found in the stool of these patients [27-29]. To find evidence for a mixed infection, we compared peak profiles of paired fecal samples and strains and observed 1-3 peaks difference in 4/65 paired samples. However, 3 of these profiles showed (an) extra peak(s) in the strain sample, while only one sample had one extra peak in the fecal sample. This could be an indication of a mixed infection in 1/65 samples $(1.5 \%)$, this is lower than the expected percentage of mixed infections described in the literature.

A major advantage of the technique we describe is the use of high-resolution capillary gel-based electrophoresis (CE-ribotyping) instead of the conventional agarose gelbased technique [15]. With CE-ribotyping it is possible to obtain digital data and reach high levels of discrimination and reproducibility, which improves standardization of C. difficile ribotyping $[18,30]$.

A limitation of our study is the relatively small number of samples that we tested and the relatively higher number of samples with RT017, due to an outbreak. However, our set contains all major ribotypes circulating in the Netherlands, which we consider sufficient to demonstrate that direct ribotyping on fecal material is possible and accurate [31, 32]. Another limitation is that our method does not distinguish between a $C$. difficile infection or colonization, as is the case with any qPCR for diagnosis of CDI, although cycle threshold values seem to correlate with presence of free toxin [33, 34].
Therefore, a positive $C$. difficile toxin gene PCR should be followed by a positive a toxin A/B EIA to confirm the diagnosis, as recommended by the European Society of Clinical Microbiology and Infectious Diseases (ESCMID) [35]. Furthermore, the diagnosis should always be based on laboratory tests in combination with clinical symptoms or signs of CDI.

The approach described here still shows some variation in banding patterns. In low load samples, one or two bands from longer fragments may be lost. This can be a consequence of partial inhibition of the PCR reaction. This might be caused by the fact that larger DNA fragments require a longer interaction with the polymerase and the chance of an error during the annealing phase is higher. Stool broth enrichment might be an option to increase direct ribotyping success rate in samples that were unsuccessfully ribotyped [27]. In one sample, we observed that the three largest DNA fragments in the strain profile were missing in the profile of the fecal sample. We think that partial inhibition might have occurred in this sample, since the three largest DNA fragments were lacking, and it appears that large fragments are most prone to partial inhibition of the PCR reaction. Since the $\mathrm{Cp}$ value was 29 , the inhibition cannot be explained by a low $C$. difficile load. However, since the bands were missing in the fecal sample but not in the cultured strain, we think that the feces contained specific inhibitory substances that were not present in the cultured isolate. As current ribotyping definitions consider a single band difference as a difference in ribotype, definitive assignment to ribotypes is not feasible yet. However, by using profilebased clustering the essential information for detection of $C$. difficile outbreaks can be provided.

Currently, ribotyping is still the most frequently used typing technique for general epidemiological surveys on CDI, though whole genome (or core genome) MLST (MultiLocus Sequence Typing) is increasingly used to study transmission of $C$. difficile [36, 37]. However, most of these techniques are more costly and time-consuming. At this moment, the whole process from submitting a feces sample and determining a PCR ribotype takes approximately 6 days. Our test is a PCR that can be applied directly on total fecal DNA and provides direct information on both the presence and the type of C. difficile. Many local diagnostic clinical microbiological laboratories nowadays only perform fecal $C$. difficile toxin gene PCR for diagnostics and hence do not culture strains for downstream molecular analysis. Since the number of laboratories with DNA sequencing devices is increasing, our technique might also become available to many local diagnostic laboratories in the near future. $C$. difficile ribotyping directly on feces could allow accelerated screening for bacterial transmission in an outbreak 
setting. If more detailed typing is desired, strains can be sent to a $C$. difficile reference laboratory for conventional ribotyping or MLST.

\section{Conclusions}

We showed that $C$. difficile ribotyping and simultaneous toxin gene detection directly on fecal samples is feasible, with equal sensitivity as qPCR. This application allows for detection of $C$. difficile infection with concomitant rapid screening for bacterial transmission between patients. This may result in more timely application of infection control measures and could therefore help in limiting $C$. difficile outbreaks.

\section{Supplementary Information}

The online version contains supplementary material available at https://doi. org/10.1186/s13756-020-00881-9.

Additional file 1: Table 1. Details of primers used for $C$. difficile ribotyping and toxin gene detection directly on fecal samples. Table $\mathbf{2}$. Details of all 65 fecal samples with positive qPCR for $C$. difficile toxin A and/or B genes and their 65 corresponding cultured strains.

\section{Acknowledgements}

Reference ribotypes were kindly provided by the Dutch National Reference Laboratory for C. difficile (LUMC, Leiden, The Netherlands). Parts of this work have been presented at ASM Microbe (Boston, Massachusetts, USA, 2016), European Congress of Clinical Microbiology and Infectious Diseases (Madrid, Spain, 2018; Amsterdam, The Netherlands, 2019), Scientific Spring Meetings of the Nederlandse Vereniging voor Medische Microbiologie meetings (Papendal, The Netherlands, 2016 and 2018) and Clostpath11 (Leiden, The Netherlands, 2019).

\section{Authors' contributions}

J.P., C.M.J.E.V. and A.E.B. conceived the study. T.M.R, J.P., C.M.J.E.V. and A.E.B. designed the study. T.M.R., J.P. and A.E.B. analyzed the data. A.K., M.J. and R.H acquired the data. T.M.R. drafted the manuscript. E.K. collaborated on behalf of the Dutch National Reference Laboratory for C. difficile. All authors critically revised the manuscript and approved the final version.

\section{Funding}

T.M.R. was supported by Netherlands Organization for Health Research and Development (ZonMw) grant Goed Gebruik Geneesmiddelen, project number 848016009. The funders had no role in study design, data collection and interpretation, or the decision to submit the work for publication.

\section{Availability of data and materials}

Details of the sample set used in the current study are shown in Additional file 1: Table 2. The datasets used and analyzed during this study are available from the corresponding author on reasonable request.

\section{Ethics approval and consent to participate}

The Medical Ethics Committee of Amsterdam UMC waived the need for ethics approval and the need to obtain consent for the collection, analysis and publication of the retrospectively obtained and anonymized data for this non-interventional study.

\section{Consent for publication}

Not applicable.

\section{Competing interests}

A.E.B. is co-founder and owner of inBiome BV, a spin-off company of Amsterdam UMC, Vrije Universiteit Amsterdam, that provided the e-Mix.

\section{Author details}

${ }^{1}$ Department of Medical Microbiology and Infection Control, Amsterdam Infection and Immunity Institute, Amsterdam UMC, Vrije Universiteit Amsterdam, PK 2X132, De Boelelaan 1117, Amsterdam, The Netherlands. ${ }^{2}$ Center for Infectious Diseases, Department of Medical Microbiology, Leiden University Medical Center, Albinusdreef 2, Leiden, The Netherlands. ${ }^{3}$ inBiome B.V., Science park 106, Amsterdam, The Netherlands.

Received: 6 July 2020 Accepted: 26 December 2020

Published online: 29 January 2021

\section{References}

1. Kwon JH, Olsen MA, Dubberke ER. The morbidity, mortality, and costs associated with Clostridium difficile infection. Infect Dis Clin North Am. 2015;29(1):123-34.

2. Smits WK, Lyras D, Lacy DB, Wilcox MH, Kuijper EJ. Clostridium difficile infection. Nat Rev Dis Primers. 2016;2:16020.

3. Ryan P, Skally M, Duffy F, Farrelly M, Gaughan L, Flood P, et al. Evaluation of fixed and variable hospital costs due to Clostridium difficile infection: institutional incentives and directions for future research. J Hosp Infect. 2017;95(4):415-20.

4. van Beurden $\mathrm{YH}$, Bomers MK, van der Werff SD, Pompe E, Spiering S, Vandenbroucke-Grauls C, et al. Cost analysis of an outbreak of Clostridium difficile infection ribotype 027 in a Dutch tertiary care centre. J Hosp Infect. 2017;95(4):421-5.

5. Merrigan M, Venugopal A, Mallozzi M, Roxas B, Viswanathan VK, Johnson S, et al. Human hypervirulent Clostridium difficile strains exhibit increased sporulation as well as robust toxin production. J Bacteriol. 2010;192(19):4904-11.

6. Hubert B, Loo VG, Bourgault AM, Poirier L, Dascal A, Fortin E, et al. A portrait of the geographic dissemination of the Clostridium difficile North American pulsed-field type 1 strain and the epidemiology of C. difficileassociated disease in Quebec. Clin Infect Dis. 2007:44(2):238-44.

7. Kuijper EJ, Coignard B, Tull P. Emergence of Clostridium difficileassociated disease in North America and Europe. Clin Microbiol Infect. 2006;12(Suppl 6):2-18.

8. Krutova M, Kinross P, Barbut F, Hajdu A, Wilcox MH, Kuijper EJ, et al. How to: surveillance of Clostridium difficile infections. Clin Microbiol Infect. 2018;24(5):469-75.

9. Gurtler V. Typing of Clostridium difficile strains by PCR-amplification of variable length 16S-23S rDNA spacer regions. J Gen Microbiol. 1993;139(12):3089-97.

10. O'Neill GL, Ogunsola FT, Brazier JS, Duerden BI. Modification of a PCR ribotyping method for application as a routine typing scheme for Clostridium difficile. Anaerobe. 1996;2(4):205-9.

11. Stubbs SL, Brazier JS, O'Neill GL, Duerden BI. PCR targeted to the $16 \mathrm{~S}-23 \mathrm{~S}$ rRNA gene intergenic spacer region of Clostridium difficile and construction of a library consisting of 116 different PCR ribotypes. J Clin Microbiol. 1999;37(2):461-3.

12. Bidet P, Barbut F, Lalande V, Burghoffer B, Petit JC. Development of a new PCR-ribotyping method for Clostridium difficile based on ribosomal RNA gene sequencing. FEMS Microbiol Lett. 1999;175(2):261-6.

13. Bidet $P$, Lalande V, Salauze B, Burghoffer B, Avesani V, Delmee $M$, et al. Comparison of PCR-ribotyping, arbitrarily primed PCR, and pulsed-field gel electrophoresis for typing Clostridium difficile. J Clin Microbiol. 2000;38(7):2484-7.

14. Indra A, Huhulescu S, Schneeweis M, Hasenberger P, Kernbichler S, Fiedler A, et al. Characterization of Clostridium difficile isolates using capillary gel electrophoresis-based PCR ribotyping. J Med Microbiol. 2008;57(Pt 11):1377-82.

15. Janezic S, Strumbelj I, Rupnik M. Use of modified PCR ribotyping for direct detection of Clostridium difficile ribotypes in stool samples. J Clin Microbiol. 2011;49(8):3024-5.

16. Quast C, Pruesse E, Yilmaz P, Gerken J, Schweer T, Yarza P, et al. The SILVA ribosomal RNA gene database project: improved data processing and web-based tools. Nucleic Acids Res. 2013;41(Database issue):D590-6.

17. Persson S, Torpdahl M, Olsen KE. New multiplex PCR method for the detection of Clostridium difficile toxin $A(t c d A)$ and toxin $B(t c d B)$ and the 
binary toxin (cdtA/cdtB) genes applied to a Danish strain collection. Clin Microbiol Infect. 2008;14(11):1057-64.

18. Fawley WN, Knetsch CW, MacCannell DR, Harmanus C, Du T, Mulvey MR, et al. Development and validation of an internationally-standardized, high-resolution capillary gel-based electrophoresis PCR-ribotyping protocol for Clostridium difficile. PLoS ONE. 2015;10(2):e0118150.

19. Rupnik M. Heterogeneity of large clostridial toxins: importance of Clostridium difficile toxinotypes. FEMS Microbiol Rev. 2008;32(3):541-55.

20. Stubbs S, Rupnik M, Gibert M, Brazier J, Duerden B, Popoff M. Production of actin-specific ADP-ribosyltransferase (binary toxin) by strains of Clostridium difficile. FEMS Microbiol Lett. 2000;186(2):307-12.

21. Gerding DN, Johnson S, Rupnik M, Aktories K. Clostridium difficile binary toxin CDT: mechanism, epidemiology, and potential clinical importance. Gut Microbes. 2014;5(1):15-27.

22. Perelle S, Gibert M, Bourlioux P, Corthier G, Popoff MR. Production of a complete binary toxin (actin-specific ADP-ribosyltransferase) by Clostridium difficile CD196. Infect Immun. 1997;65(4):1402-7.

23. Azimirad M, Naderi Noukabadi F, Lahmi F, Yadegar A. Prevalence of binary-toxin genes (cdtA and cdtB) among clinical strains of Clostridium difficile isolated from diarrheal patients in Iran. Gastroenterol Hepatol Bed Bench. 2018;11(Suppl 1):59-65.

24. Kim J, Kim Y, Pai H. Clinical Characteristics and Treatment Outcomes of Clostridium difficile Infections by PCR Ribotype 017 and 018 Strains. PLoS ONE. 2016;11(12):e0168849.

25. Cairns MD, Preston MD, Hall CL, Gerding DN, Hawkey PM, Kato H, et al. Comparative genome analysis and global phylogeny of the toxin variant Clostridium difficile PCR ribotype 017 reveals the evolution of two independent sublineages. J Clin Microbiol. 2017;55(3):865-76.

26. Seugendo M, Janssen I, Lang V, Hasibuan I, Bohne W, Cooper P, et al. Prevalence and strain characterization of clostridioides (Clostridium) difficile in representative regions of Germany, Ghana, Tanzania and Indonesia-a comparative multi-center cross-sectional study. Front Microbiol. 2018;9:1843.

27. Lloyd CD, Shah-Gandhi B, Parsons BD, Morin SBN, Du T, Golding GR, et al. Direct Clostridioides difficile ribotyping from stool using capillary electrophoresis. Diagn Microbiol Infect Dis. 2020;99(3):115259.

28. Dayananda P, Wilcox MH. A review of mixed strain Clostridium difficile colonization and infection. Front Microbiol. 2019;10:692.

29. van den Berg RJ, Ameen HA, Furusawa T, Claas EC, van der Vorm ER, Kuijper EJ. Coexistence of multiple PCR-ribotype strains of Clostridium difficile in faecal samples limits epidemiological studies. J Med Microbiol. 2005;54(Pt 2):173-9.

30. Killgore G, Thompson A, Johnson S, Brazier J, Kuijper E, Pepin J, et al. Comparison of seven techniques for typing international epidemic strains of Clostridium difficile: restriction endonuclease analysis, pulsed-field gel electrophoresis, PCR-ribotyping, multilocus sequence typing, multilocus variable-number tandem-repeat analysis, amplified fragment length polymorphism, and surface layer protein A gene sequence typing. J Clin Microbiol. 2008:46(2):431-7.

31. difficile DNRLfC. Eleventh annual report of the National Reference Laboratory for Clostridium difficile and results of the sentinel surveillance, May 2016-May 2017. Website of the Dutch National Institute for Public Health and the Environment (Rijksinstituut voor Volksgezondheid en Milieu); 2017.

32. difficile DNRLfC. Tenth annual report of the National Reference Laboratory for Clostridium difficile and results of the sentinel surveillance, May 2015May 2016. Website of the Dutch National Institute for Public Health and the Environment (Rijksinstituut voor Volksgezondheid en Milieu); 2016.

33. Senchyna F, Gaur RL, Gombar S, Truong CY, Schroeder LF, Banaei N. Clostridium difficile PCR cycle threshold predicts free toxin. J Clin Microbiol. 2017;55(9):2651-60.

34. Shah MD, Balada-Llasat JM, Coe K, Reed E, Sandlund J, Pancholi P. Evaluation of cycle threshold, toxin concentration, and clinical characteristics of Clostridioides difficile infection in patients with discordant diagnostic test results. J Clin Microbiol. 2020;58(5):e0168119.

35. Crobach MJ, Planche T, Eckert C, Barbut F, Terveer EM, Dekkers OM, et al. European Society of Clinical Microbiology and Infectious Diseases: update of the diagnostic guidance document for Clostridium difficile infection. Clin Microbiol Infect. 2016;22(Suppl 4):S63-81.

36. Janezic S, Rupnik M. Development and implementation of whole genome sequencing-based typing schemes for Clostridioides difficile. Front Public Health. 2019;7:309.

37. Griffiths D, Fawley W, Kachrimanidou M, Bowden R, Crook DW, Fung R, et al. Multilocus sequence typing of Clostridium difficile. J Clin Microbiol. 2010;48(3):770-8.

\section{Publisher's Note}

Springer Nature remains neutral with regard to jurisdictional claims in published maps and institutional affiliations.
Ready to submit your research? Choose BMC and benefit from:

- fast, convenient online submission

- thorough peer review by experienced researchers in your field

- rapid publication on acceptance

- support for research data, including large and complex data types

- gold Open Access which fosters wider collaboration and increased citations

- maximum visibility for your research: over $100 \mathrm{M}$ website views per year

At BMC, research is always in progress.

Learn more biomedcentral.com/submissions 